\title{
Different limb lengths in gastric bypass surgery: study protocol for a Swiss multicenter randomized controlled trial (SLIM)
}

Marko Kraljević ${ }^{1 \dagger}$ (D), Romano Schneider ${ }^{1+}$, Bettina Wölnerhanssen ${ }^{2}$, Marco Bueter $^{3}$, Tarik Delko ${ }^{1}$ and Ralph Peterli ${ }^{1 *}$

\begin{abstract}
Background: Obesity and type 2 diabetes mellitus are reaching epidemic proportions. In morbidly obese patients, bariatric operations lead to sustained weight loss and relief of comorbidities in the majority of patients. Laparoscopic Roux-Y-gastric bypass (RYGB) is one of the most frequently performed operations, but it is still unknown why some patients respond better than others. Therefore, a number of variations of this operation have been introduced. Recent evidence suggests that a longer bypassed biliopancreatic limb (BPL) has the potential to be more effective compared to the standard RYGB with a shorter BPL length. This article describes the design and protocol of a randomized controlled trial comparing the outcome of a RYGB operation with a long versus short BPL.
\end{abstract}

Methods/design: The trial is designed as a multicenter, randomized, patient- and observer-blinded trial. The relevant ethics committee has approved the trial protocol. To demonstrate that long BPL RYGB is superior compared to short BPL RYGB in terms of weight loss and resolution of T2DM, the study is conducted as a superiority trial. Postoperative percent total weight loss and nutritional deficiency rate are the primary endpoints, whereas morbidity, mortality, remission of obesity-related comorbidities and quality of life are secondary endpoints. Eight hundred patients, between 18 and 65 years and with a body mass index (BMI) from 35 to $60 \mathrm{~kg} / \mathrm{m}^{2}$ who meet the regulatory rules for bariatric surgery in Switzerland, will be randomized. The endpoints and baseline measurements will be assessed pre-, intra-, and postoperatively.

Discussion: With its high number of patients and a 5-year follow-up, this study will answer questions about effectiveness and safety of long BPL RYGB and provide level I evidence for improvement of the standard RYGB. These findings might therefore potentially influence global bariatric surgery guidelines.

Trial registration: ClinicalTrials.gov NCT04219787. Registered on 7 January 2020.

Keywords: Randomized controlled trial, Roux-en-Y gastric bypass, Different limb lengths, Weight loss

\footnotetext{
* Correspondence: ralph.peterli@clarunis.ch

${ }^{\dagger}$ Marko Kraljević and Romano Schneider contributed equally to this work.

'Clarunis, Department of Visceral Surgery, University Center for

Gastrointestinal and Liver Diseases, St. Clara Hospital and University Hospital Basel, 4002 Basel, Switzerland

Full list of author information is available at the end of the article
}

(c) The Author(s). 2021 Open Access This article is licensed under a Creative Commons Attribution 4.0 International License, which permits use, sharing, adaptation, distribution and reproduction in any medium or format, as long as you give appropriate credit to the original author(s) and the source, provide a link to the Creative Commons licence, and indicate if changes were made. The images or other third party material in this article are included in the article's Creative Commons licence, unless indicated otherwise in a credit line to the material. If material is not included in the article's Creative Commons licence and your intended use is not permitted by statutory regulation or exceeds the permitted use, you will need to obtain permission directly from the copyright holder. To view a copy of this licence, visit http://creativecommons.org/licenses/by/4.0/ The Creative Commons Public Domain Dedication waiver (http://creativecommons.org/publicdomain/zero/1.0/) applies to the data made available in this article, unless otherwise stated in a credit line to the data. 


\section{Background}

The rising prevalence of morbid obesity is causing a major health burden in terms of morbidity and mortality [1]. Complications of obesity, especially type 2 diabetes mellitus (T2DM), are placing a growing demand on healthcare resources. The prevalence of T2DM increases parallel to obesity and currently; there are 55.2 million people with T2DM in Europe, accounting for $8.5 \%$ of the adult population [2]. About half of the obesityassociated healthcare costs in Switzerland are attributed to diabetes [3]. Morbid obesity is a chronic disease for which multimodal therapeutic management strategies are necessary, comparable to cancer treatment, to reach partial or full remission with a persistent risk of relapse and thus, long-lasting follow-up is mandatory. Medical therapeutic strategies (diet, behavioral changes, or drugs) to achieve and maintain clinically significant weight loss remain limited [4].

Bariatric surgery is currently the most effective treatment for morbid obesity [4-7]. Although laparoscopic sleeve gastrectomy has become the most commonly performed bariatric procedure worldwide [8], laparoscopic Roux-en-Y gastric bypass (RYGB) is the most frequently performed bariatric procedure in Switzerland. From a scientific point of view, it is no longer a question if this procedure has a significant effect on metabolic control, but rather how the outcomes after RYGB can be further improved.

Since its introduction in 1967 by Mason [9], there have been many multiple technical variations of the RYGB to increase weight loss. Most studies used an alimentary limb (AL) length of 100 to $150 \mathrm{~cm}$ and a biliopancreatic limb (BPL) length of 50 to $120 \mathrm{~cm}$, while the common limb $(\mathrm{CL})$ length remained not measured $[10,11]$.

Scopinaro et al. [12] developed the biliopancreatic diversion (BPD) technique in 1979 and concluded that the BPD seems to be the most powerful treatment for hyperlipidemia and T2DM. Available evidence suggests that the extended BPL length in patients after BPD may be one of the key factors explaining the superiority of this procedure, which is further supported by some observational studies reporting greater weight loss in patients after RYGB with a longer BPL [13-15].

To this day, only one randomized controlled trial (RCT) [16] compared long BPL RYGB (150 cm BPL, AL $75 \mathrm{~cm}$ ) with a short BPL RYGB (BPL $75 \mathrm{~cm}, \mathrm{AL} 150 \mathrm{~cm}$ ) in 128 patients and found a significant increase in percent excess weight loss (\%EWL) for patients with long BPL RYGB in the first 4 years after surgery. However, the underlying mechanism of a greater weight loss after long BPL RYGB remains unclear. Furthermore, lengthening of the BPL cannot be done limitless as it carries an increasing risk of severe malnutrition. Neither of the two procedures seems to be technically more challenging, since the complication rates did not show any significant difference [16]. However, a limitation of this study was the cohort of 146, which was too small to show any advantage in terms of comorbidities resolution or quality of life changes.

Therefore, our aim is to investigate if a longer BPL in RYGB leads to greater weight loss and superior remission of comorbidities in morbidly obese patients without reducing its safety. No matter which outcome will be obtained, our results will provide level I evidence for an improvement of the standard laparoscopic RYGB and thus may potentially influence global bariatric surgery guidelines.

\section{Methods/design}

The overall objective of this study is to evaluate whether long BPL RYGB is superior compared to short BPL RYGB in treating morbid obesity and the associated comorbidities.

\section{Primary objective}

The primary objective of this study is to show that long BPL leads to a greater percent total weight loss (\%TWL, superiority), while not leading to a larger nutritional deficiency rate (non-inferiority) at 1-, 3-, and 5-year follow-up.

\section{Secondary objective}

The secondary objectives are to assess the percent excess body mass index loss (\%EBMIL), remission of comorbidities, complication rate/safety, and quality of life 1, 3, and 5 years after long and short BPL RYGB.

\section{Study design and site}

This is a multicenter, randomized, controlled, patientand observer-blinded, superiority trial in morbidly obese patients receiving either long BPL or short BPL RYGB. All participating centers (4 university hospitals and 11 cantonal, regional, and private hospitals) have knowledge and experience in bariatric surgery and were certified as Bariatric Reference Centers by the Swiss Society for the Study of Morbid Obesity and Metabolic Disorders (SMOB). The trial has been registered on ClinicalTrials.gov under the identifier NCT04219787. This protocol has been written in accordance with the Standard Protocol Items: Recommendations for Interventional Trials (SPIRIT) guidelines (Additional file 1). The planned visit and examination schedule is presented in Fig. 1.

\section{Inclusion criteria}

Participants fulfilling the following criteria are eligible for the study: 


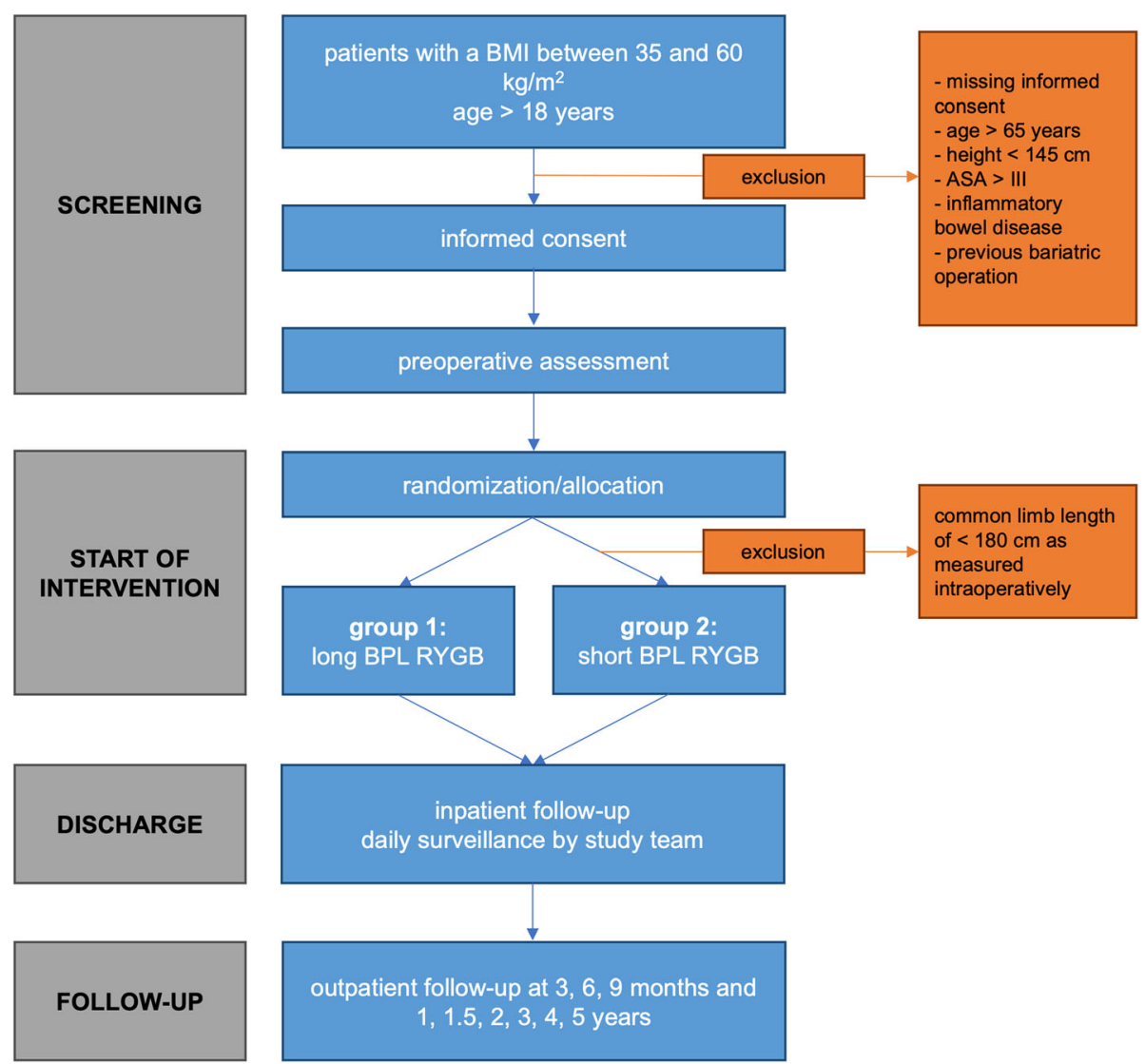

Fig. 1 Schedule of enrollment, interventions, and assessments according to the Standard Protocol Items: Recommendations for Interventional Trials (SPIRIT) guideline

- Informed consent (IC) as documented by signature (Appendix Informed Consent Form)

- Patients with BMI of $35 \mathrm{~kg} / \mathrm{m}^{2}$ or higher who comply with the regulatory rules for bariatric surgery in Switzerland (SMOB guidelines [17])

\section{Exclusion criteria}

The presence of any one of the following exclusion criteria will lead to exclusion of the participant:

- Age $<18$ years or $>65$ years

- $\mathrm{BMI}>60 \mathrm{~kg} / \mathrm{m}^{2}$

- Height $<145 \mathrm{~cm}$

- CL length of $<180 \mathrm{~cm}$ as measured intraoperatively

- ASA physical status classification > III

- Previous bariatric operation

- Inflammatory bowel disease

- Ongoing malignant disease

- Known or suspected non-compliance, drug or alcohol abuse

- Psychiatric disorder

\section{Randomization}

Eligible patients, who give written confirmed consent, will be registered in the electronic data capture and management system secuTrial ${ }^{\circ}$, which is programmed by the Clinical Trial Unit (CTU) of the University of Basel. The database is web-based and allows online randomization stratified by the involved centers. An allocation ratio of 1 : 1 with a block size of 4 will ensure a balance in sample size across both groups over time. The randomization allocation will only be known to the CTU staff. Patients will be enrolled and randomly assigned by the surgeon to receive a long BPL RYGB (arm A) versus a short BPL RYGB (arm B). Figure 2 provides a schematic view of both types of RYGBs.

\section{Interventions}

All patients will receive standard preoperative assessment including endocrine, pulmonary function and cardiovascular assessment, psychiatric assessment, gastroscopy with Helicobacter pylori testing, and abdominal ultrasound to check for liver size and gallstones. Patients in arm A will receive a RYGB with a $180-\mathrm{cm}$-long BPL and an AL of 80 

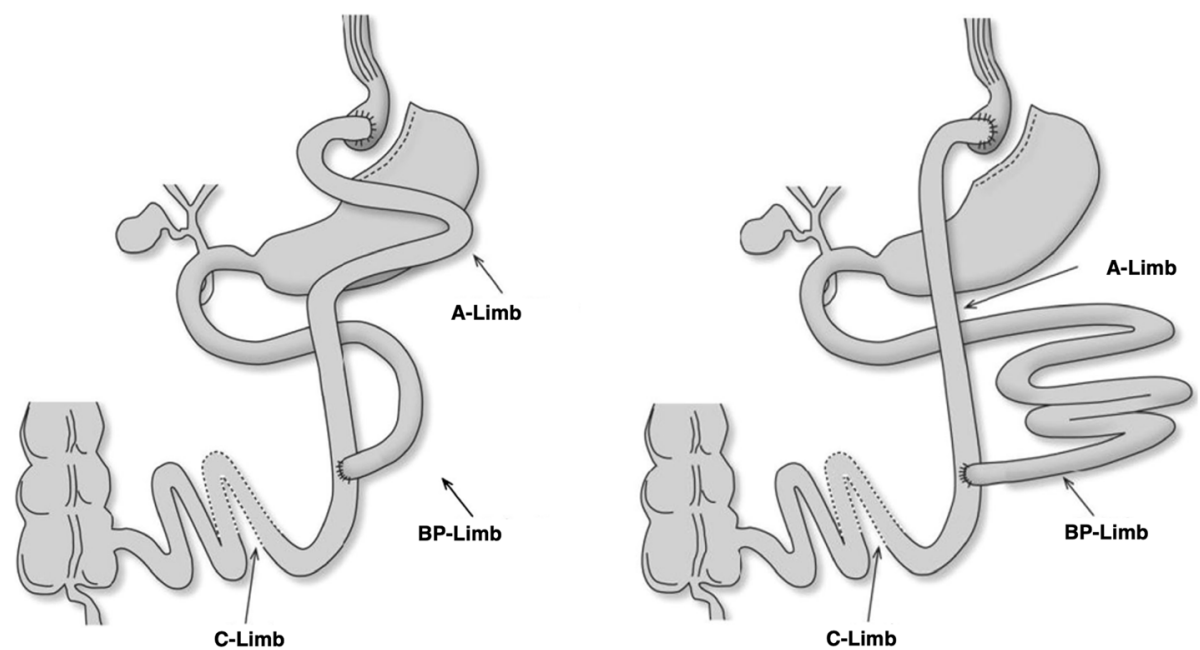

Fig. 2 Enrolled patients receive a Roux-en-Y gastric bypass either with long biliopancreatic limb (BP-limb) and short alimentary limb (A-limb) or short biliopancreatic limb and long alimentary $\operatorname{limb}(\mathrm{A}-\mathrm{limb})$. The common $\operatorname{limb}(\mathrm{C}-\mathrm{limb})$ should remain the same for both groups

$\mathrm{cm}$; the group B will receive a RYGB with an $80-\mathrm{cm}$ BPL and a $180-\mathrm{cm}$ AL. The individual technique in terms of trocar position, materials used (i.e., staplers, trocar, suture) will be left to the choice of each individual surgeon. Total small bowel length will be measured during surgery; patients with a total small bowel length of less than $440 \mathrm{~cm}$ will be excluded from the study. Patient- and observerblinded pre- and postoperative follow-up will be performed. There are no strategies for patients to improve adherence to intervention protocol since this is a surgical trial. All participating centers and surgeons are experienced bariatric surgeons with a minimal total caseload of more than 200 bariatric procedures and more than 50 surgeries per year. In order to make surgeons adhere to intervention protocol, all critical surgical steps (e.g., pouch size, total bowel length measurement, technique of Roux-limb and gastroenterostomy construction, closure of mesenteric defects, and operation time) will be documented in our database. The non-adherent cases will be excluded from per-protocol analysis. There will be no criteria for modifying the operative procedures.

\section{Study visits}

Physicians blinded to the intervention will perform study documentation and patient assessment. Since the trial is designed as an observer and patient blinded RCT, information about the surgical procedure will not be disclosed during the follow-up examinations to any assessors. There will be 11 study visits in total. The study design flow diagram is presented in Table 1. Potential study participants will be identified by the preoperative outpatient clinic consultations. The first visit will be preoperative after informed consent is obtained.
Then patients will receive their study intervention according to the preoperative randomization. Postoperatively, study visits will be performed at discharge, 3, 6, 9, 12 , and 18 months and 2, 3, 4, and 5 years. Each study visit includes data collection of weight, blood tests (e.g., hemoglobin, creatinine, urea, uric acid, calcium, Creactive protein, albumin, liver function tests, fasting glucose, HbA1c, vitamins A, B1, B6, B12, and D, parathormone, ferritin, folate, zinc, cholesterol, lipoproteins, and triglycerides), and complications. In addition, questionnaires will be also assessed to study the quality of life (Bariatric Analysis and Reporting Outcome System [BAROS] [18] and the Gastrointestinal Quality of Life Index [GIQLI] [19]), the Arts questionnaire [20] to determine postoperative determine dumping syndrome and questionnaire for quantification of frequency and severity of potential diarrhea.

\section{Study endpoints \\ Primary endpoint}

The primary endpoints are \%TWL and the number of nutritional deficiencies 1,3 , and 5 years postoperatively. For the \%TWL the presurgical weight (at hospital entry time of the patient) and postsurgical weight at the corresponding visit will be measured.

\section{Secondary endpoints}

- \%EBMIL

- Remission of comorbidities

- Complication rate

- Quality of life 
Table 1 Schedule of study assessments

\begin{tabular}{|c|c|c|c|c|c|c|c|c|c|c|c|}
\hline Study periods & Screening & Intervention & Follow-u & & & & & & & & \\
\hline Visit & 1 & 2 & 3 & 4 & 5 & 6 & 7 & 8 & 9 & 10 & 11 \\
\hline Time (day, month, year) & $\begin{array}{l}-3 \\
\text { months }\end{array}$ & $0-5$ days & $\begin{array}{l}3 \\
\text { months }\end{array}$ & $\begin{array}{l}6 \\
\text { months }\end{array}$ & $\begin{array}{l}9 \\
\text { months }\end{array}$ & $\begin{array}{l}1 \\
\text { year }\end{array}$ & $\begin{array}{l}1.5 \\
\text { years }\end{array}$ & $\begin{array}{l}2 \\
\text { years }\end{array}$ & $\begin{array}{l}3 \\
\text { years }\end{array}$ & $\begin{array}{l}4 \\
\text { years }\end{array}$ & $\begin{array}{l}5 \\
\text { years }\end{array}$ \\
\hline $\begin{array}{l}\text { Patient information and informed } \\
\text { consent }\end{array}$ & $x$ & & & & & & & & & & \\
\hline Demographics & $x$ & & & & & & & & & & \\
\hline Medical history & $x$ & & & & & & & & & & \\
\hline Inclusion/exclusion criteria & $x$ & $x$ & & & & & & & & & \\
\hline Physical examination & $x$ & $x$ & $x$ & $x$ & $x$ & $x$ & $x$ & $x$ & $x$ & $x$ & $x$ \\
\hline Vital signs & $x$ & $x$ & $x$ & $x$ & $x$ & $x$ & $x$ & $x$ & $x$ & $x$ & $x$ \\
\hline Laboratory tests & $x$ & $x$ & $x$ & $x$ & $x$ & $x$ & $x$ & $x$ & $x$ & $x$ & $x$ \\
\hline Randomization & & $x$ & & & & & & & & & \\
\hline Operation & & $x$ & & & & & & & & & \\
\hline Complications & & $x$ & $x$ & $x$ & $x$ & $x$ & $x$ & $x$ & $x$ & $x$ & $x$ \\
\hline Primary variables & $x$ & $x$ & $x$ & $x$ & $x$ & $x$ & $x$ & $x$ & $x$ & $x$ & $x$ \\
\hline Secondary variables & $x$ & $x$ & $x$ & $x$ & $x$ & $x$ & $x$ & $x$ & $x$ & $x$ & $x$ \\
\hline Questionnaires & $x$ & & & $x$ & & $x$ & & $x$ & $x$ & $x$ & $x$ \\
\hline Adverse events & & $x$ & $x$ & $x$ & $x$ & $x$ & $x$ & $x$ & $x$ & $x$ & $x$ \\
\hline
\end{tabular}

All comorbidities will be assessed at 3, 6, 9, 12, and 18 months and 2, 3, 4, and 5 years by a physician based on symptoms, laboratory findings, and use of medication. The postoperative course of comorbidities will be defined as follows: remission: no symptoms/without any medication (dyslipidemia true remission $=$ no medica tion and normal lipid values); remission of T2DM will be defined according to the ADA criteria: complete remission: HbA1c $<6.0 \%$, fasting glucose $<100 \mathrm{mg} / \mathrm{dl}$ and at least one year no active pharmacologic therapy; partial remission $\mathrm{HbA} 1 \mathrm{c}<6.5 \%$ [21]; improvement: less symptoms and/or less medical treatment/medication; unchanged: same symptoms and equivalent therapy; worsened: more symptoms or increase of therapy; de novo comorbidity: comorbidity not present at baseline, but newly developed within 5 years postoperatively. All surgical and non-surgical complications will be assessed according to the Clavien-Dindo classification (CDC) [22] and the Comprehensive Complication Index (CCI) [23]. The Arts score will help to identify potential dumping syndrome. BAROS and GIQLI scores will be used to measure postoperative quality of life.

\section{Blinding}

With exception of the team in the operating theater, all involved medical and non-medical practitioners are blinded as well as the patient. The procedure will be named as laparoscopic Roux-en-Y gastric bypass in all medical records without mentioning the limb lengths. Unblinding is permitted at the end of the study and in case of surgical or medical complications, emergency consultation, or other ethical considerations. The operating surgeon will not be involved in any decisions that influence the primary endpoint or in judgement of the primary endpoint. Furthermore, the efficacy of blinding measures will be regularly assessed according to by Probst et al. [24].

\section{Study management and administration}

Data management and monitoring is supported by the CTU of the University of Basel. Source data of every study participant are entered into the study data management system secuTrial ${ }^{\circ}$ (interActive Systems GmbH, Berlin, Germany).

\section{Quality control measures}

Continuous central and on-site monitoring of the study is performed by the CTU for quality control and assurance purposes to evaluate the progress of the study and to verify the accuracy and completeness of eCRFs. All assessors will be trained in data entry to ensure data quality. Data entered into the eCRF will be validated for completeness and discrepancies automatically. Furthermore, the data will be reviewed by the responsible investigator as well as by an independent monitor. Furthermore, the CTU will ensure that all protocol requirements are met, and all applicable local authority regulations and investigator's obligations are being fulfilled and to resolve any inconsistency in the study records. Monitoring will consist of one initiation visit, one 
monitoring visit per year, and a close-out visit per center as a minimum.

\section{Statistical analyses Sample size}

Our study was designed to evaluate whether long BPL in RYGB has advantages compared to short BPL in terms of $\%$ weight loss (superiority) without compromising the safety in terms of nutritional deficiency rate (non-inferiority) at 5 years follow-up. For our primary outcome efficacy and safety, assuming a \%TWL of $27 \pm 10 \%$ at 5 years follow-up for short BPL with a minimal improvement of $5 \%$ TWL for long BPL to be relevant and an expected cumulative nutritional deficiency rate of $50 \%$ at 5 years follow-up with a non-inferiority margin defined at $10 \%, 400$ patients per group will be needed to reach a power of $80 \%$ with an alpha level at $5 \%$. For further details on calculations, see the "Analysis of endpoints" section below.

\section{Analysis of endpoints}

The study results will be reported in adherence to the extension of the CONSORT statement from 2010 on reporting of randomized trials [25]. Summary statistics will be used to describe and compare patient characteristics of all suitable, but non-included patients and all included patients (overall and stratified for the two treatment arms). Study endpoints will be analyzed for the intention-to-treat (ITT) population and the perprotocol (PP) population. Sensitivity analysis will be conducted for the ITT population. Thereby, the ITT population includes all randomized patients in the groups to which they were randomly assigned, regardless of their adherence with the entry criteria, regardless of the treatment they actually received, and regardless of subsequent withdrawal or deviation from the protocol. In the PP population, all protocol violators, including anyone who switched groups or missed measurements, are excluded. For each group, a number of participants (denominator) included in each analysis and whether the analysis was by original assigned groups will be given. Additional sensitivity analysis will be used if, despite all efforts taken to ensure complete data collection, the number of missing data is non-negligible or could potentially bias the results and conclusions.

\section{Analysis of primary endpoint}

The primary objective consists of two separate analyses, one for safety and one for efficacy. The difference in efficacy is tested by performing a Mann-Whitney $U$ test, thereby releasing the assumption of normality for the proportion of weight loss. The proportion of safety events during the first 5 years in each study arm is reported, including the two-sided $95 \%$ confidence interval.

\section{Analysis of secondary endpoints}

To investigate superiority of the experimental treatment in the long-term, analysis used for the primary endpoint will be repeated for \%EBMIL at 1,3 , and 5 years postoperatively. The number of peri- and post-surgical complications will be analyzed by the chi-squared or Fisher's exact test dependent on the CCI score. The other secondary endpoints will be investigated using appropriate explorative methods and graphical visualization.

\section{Ethical considerations}

Participation in this trial is strictly voluntary and patients are allowed to exit the trial at any point without explanation. All eligible patients are provided an information brochure describing the study with sufficient information for them to make an informed decision about their participation in this study.

The study protocol, patients' information sheets and informed consents were approved by the local ethic committee (Ethikkommission Nordwest- und Zentralschweiz, EKNZ 2019-02392). In addition, insurance coverage for general liability has been obtained.

Patients who decline to participate in this study are treated according to clinical standards. These patients will not be included and no study-specific follow-up will be performed.

\section{Participants' confidentiality}

The participants' confidentiality is maintained at all times. For confidentiality reasons, electronic case report forms (eCRF) do not contain any personal data of study participants. Members of the ethics committees are obliged to respect confidentiality and to refrain from divulging the participants' identity or any other personal information they might be aware of. Source data in the hospital's electronic patient information systems are secured by personal passwords and handled with respect to medical secrecy.

\section{Archiving and data retention}

The investigator will maintain all study-related records, such as eCRFs, medical records, laboratory reports, informed consent documents, safety reports, information regarding participants who discontinued, and other pertinent data. All records will be retained by the investigator as long as required by the applicable laws and regulatory requirements (10 years). Thereafter, all data will be destroyed. The study is conducted in compliance with this protocol and according to Good Clinical Practice standards as well as legal regulations. Direct access to source documents will be permitted for purposes of monitoring, audits, and inspections. 


\section{Dissemination policy}

The results of the study will be published in a peerreviewed medical journal and presented at national and international scientific conferences. Authorships will be based on the recommendations of the International Committee of Medical Journal Editors.

\section{Discussion}

The positive effects of bariatric surgery on weight loss, obesity-related comorbidities, and mortality have been widely demonstrated in long-term cohort trials and short-term RCTs [26, 27]. Over time, these procedures have improved in respect to safety and can be offered at a low mortality and morbidity [28]. The sleeve gastrectomy and the RYGB are the most common surgical procedures [8]. However, the laparoscopic RYGB is still the most commonly performed bariatric procedure in Switzerland [17]. It is no longer a question, if the RYGB has a significant effect on weight loss and on obesityassociated comorbidities, but rather how to improve the procedure and its outcomes.

The RYGB is a complex anatomical concept with various parts for potential improvement including the limb lengths. For many years, the length of the $\mathrm{AL}$ was thought to be the most influential factor regarding postoperative weight loss. Therefore, previous studies focused on the effects of various AL lengths, until Choban et al. showed that lengthening the AL has no effect on weight loss [29]. In contrast, the effect of the BPL length on weight loss has been studied to a much lesser extent. While the non-randomized study by Leifsson et al. reported excellent weight loss in patients with long BPL [14], only one RCT addressed this question after RYGB so far [16]. Here, the authors compared long BPL RYGB $(150 \mathrm{~cm}$ BPL, AL $75 \mathrm{~cm})$ with a short BPL RYGB (BPL $75 \mathrm{~cm}$, AL $150 \mathrm{~cm}$ ) in 128 patients and found a significant increase in \%EWL for patients with long BPL RYGB 4 years after surgery. However, lengthening the BPL is not unlimited due to the increased risk of malnutrition [30]. Several studies suggest a minimal total alimentary limb length of $300 \mathrm{~cm}$, which is defined as an added value of the $\mathrm{AL}$ and the $\mathrm{CL}$, to reduce the risk of malnutrition with deficiencies of micro- and macronutrients [31-33].

Against this theoretical framework, it is difficult to draw conclusions on the optimal length of the AL and BPL, respectively, necessary to achieve the best possible outcome with a low risk of protein malnutrition. The most effective BPL length for the RYGB procedure has not been found yet since weight loss and improvement of comorbidities have only been evaluated in one nonrandomized study [14] and one RCT [16].

As total bowel length varies by many meters between individuals, measuring the total length and therefore knowing the dimensions of all segments involved in RYGB will lead to a better understanding of the role of each segment in the beneficial effects after RYGB. This study investigates the effectiveness of long BPL RYGB compared to short BPL RYGB, analyzing defined clinical endpoints such as weight loss, morbidity and mortality, improvement in obesity-related comorbidities, and quality of life. Furthermore, the RCT by Homan et al. [16] failed to show any significant differences in T2DM remissions as it was only powered for weight loss. Our study has enough power to address the postoperative course in terms of resolution of comorbidities.

In conclusion, the "perfect" RYGB leads to adequate \%TWL and improvement in obesity-related comorbidities without increasing the complication rate. The SLIM trial will answer questions about effectiveness and safety after long BPL RYGB and provide level I evidence for improvement of the standard RYGB. These findings might therefore potentially influence bariatric surgery guidelines on a global level.

\section{Trial status}

Protocol version number 1.1, 12 February 2020. The trial has received ethics approval by January 2020. The first patient will be randomized in June 2020. We expect to enroll the calculated sample size in a 2- to 3-year time period. Estimated end of the study is December 2027.

\section{Abbreviations}

AL: Alimentary limb; BAROS: Bariatric analysis and reporting system; BMI: Body mass index; BPD: Biliopancreatic diversion; BPL: Biliopancreatic limb; CCI: Comprehensive Complication Index; CDC: Clavien-Dindo classification; CL: Common limb; EBMIL: Excess body mass index loss; eCRF: Electronic case report form; EWL: Excess weight loss;

GIQLI: Gastrointestinal quality of life index; RYGB: Roux-en-Y gastric bypass; TALL: Total alimentary limb length; TWL: Total weight loss

\section{Supplementary Information}

The online version contains supplementary material available at https://doi. org/10.1186/s13063-021-05313-6.

Additional file 1. SPIRIT 2013 Checklist: Recommended items to address in a clinical trial protocol and related documents.

\section{Acknowledgements}

The authors would like to thank all support personnel for their hard work and dedication.

\section{Authors' contributions}

MK participated in the conception and design of the study and is responsible for the coordination of the study. He is the study coordinator and member of the steering committee. He drafted and revised this manuscript critically for important intellectual content and given final approval of this final version. He agrees to be accountable for all aspects of the work in ensuring that questions related to the accuracy or integrity of any part of the work are appropriately investigated and resolved. RS drafted and has revised this manuscript critically for important intellectual content and given final approval of this final version. He agrees to be accountable for all aspects of the work in ensuring that questions related to the accuracy or integrity of any part of the work are appropriately investigated and resolved. BW has participated in the conception and design of the study. She has 
revised this manuscript critically for important intellectual content and given final approval of this final version. She agrees to be accountable for all aspects of the work in ensuring that questions related to the accuracy or integrity of any part of the work are appropriately investigated and resolved. $\mathrm{MB}$ is part of the steering committee. He has revised this manuscript critically for important intellectual content and given final approval of this final version. He agrees to be accountable for all aspects of the work in ensuring that questions related to the accuracy or integrity of any part of the work are appropriately investigated and resolved. TD is part of the steering committee. He has revised this manuscript critically for important intellectual content and given final approval of this final version. He agrees to be accountable for all aspects of the work in ensuring that questions related to the accuracy or integrity of any part of the work are appropriately investigated and resolved. RP initiated, designed, and conceived this study. $\mathrm{He}$ is the sponsor investigator and responsible for overall study coordination. He has revised this manuscript critically for important intellectual content and given final approval of this final version. He agrees to be accountable for all aspects of the work in ensuring that questions related to the accuracy or integrity of any part of the work are appropriately investigated and resolved. The authors read and approved the final manuscript.

\section{Authors' information}

Our team has extensive experience in bariatric surgery. We have published several observational and interventional studies. Our last Swiss multicenter randomized study comparing RYGB and sleeve gastrectomy (SM-BOSS trial) was published in high-impact journals [34-36].

\section{Funding}

Funding was requested from the Swiss National Science Foundation and the University of Basel; the decisions are pending. Otherwise, no external funding was received for the trial. There are no commercial sponsors. The funder will not play any part in study design; collection, management, analysis, and interpretation of data; writing of the report; and the decision to submit the report for publication.

\section{Availability of data and materials}

All data will be available for other research groups interested in conduction systematic reviews. Requests for data should be directed to the Sponsor Investigator, Ralph Peterli, ralph.peterli@clarunis.ch.

\section{Declarations}

\section{Ethics approval and consent to participate}

The study protocol, patients' information sheets and informed consents were approved by the local ethic committee (Ethikkommission Nordwest- und Zentralschweiz, EKNZ 2019-02392). The study was also registered with the ClinicalTrials.gov registry (Registration No. NCT04219787). Written informed consent will be obtained and documented for all study participants.

\section{Consent for publication}

Not applicable.

\section{Competing interests}

The authors declare that they have no competing interests.

\section{Author details}

${ }^{1}$ Clarunis, Department of Visceral Surgery, University Center for Gastrointestinal and Liver Diseases, St. Clara Hospital and University Hospital Basel, 4002 Basel, Switzerland. ${ }^{2}$ St. Clara Research Ltd, Kleinriehenstrasse 30, 4058 Basel, Switzerland. ${ }^{3}$ Department of Visceral Surgery, University Hospital Zurich, Rämistrasse 100, 8091 Zürich, Switzerland.

\section{Received: 10 August 2020 Accepted: 5 May 2021}

\section{Published online: 19 May 2021}

\section{References}

1. Finucane MM, Stevens GA, Cowan MJ, Danaei G, Lin JK, Paciorek CJ, et al. National, regional, and global trends in body-mass index since 1980: systematic analysis of health examination surveys and epidemiological studies with 960 country-years and 9.1 million participants. Lancet. 2011; 377(9765):557-67. https://doi.org/10.1016/S0140-6736(10)62037-5.
2. Danaei G, Finucane MM, Lu Y, Singh GM, Cowan MJ, Paciorek CJ, et al. National, regional, and global trends in fasting plasma glucose and diabetes prevalence since 1980: systematic analysis of health examination surveys and epidemiological studies with 370 country-years and 2.7 million participants. Lancet. 2011;378(9785):31-40. https://doi.org/10.1016/S01406736(11)60679-X Elsevier Ltd.

3. Bundesamt für Gesundheit. Available from: https://www.bag.admin.ch/bag/ de/home/gesund-leben/gesundheitsfoerderung-und-praevention/ koerpergewicht/uebergewicht-und-adipositas/kosten-uebergewicht-und-a dipositas.html. Accessed 29 Mar 2021.

4. Sjöström L, Lindroos A-K, Peltonen M, Torgerson J, Bouchard C, Carlsson B, et al. Lifestyle, diabetes, and cardiovascular risk factors 10 years after bariatric surgery. N Engl J Med. 2004;351(26):2683-93. https://doi.org/10.1 056/NEJMoa035622.

5. Christou NV, Sampalis JS, Liberman M, Look D, Auger S, McLean APH, et al. Surgery decreases long-term mortality, morbidity, and health care use in morbidly obese patients. Ann Surg. 2004;240(3):416-24. https://doi.org/10.1 097/01.sla.0000137343.63376.19.

6. Sjöström L, Narbro K, Sjöström C, Karason K, Larsson B, Wedel H, et al. Effects of bariatric surgery on mortality in Swedish obese subjects. N Engl J Med. 2007;357(8):741-52. https://doi.org/10.1056/NEJMoa066254.

7. Adams T, Gress R, Simper Smith S, Halverson R, Simper Smith S, Rosamond W, et al. Long-term mortality after gastric bypass surgery. N Engl J Med. 2007;357(8):753-61. https://doi.org/10.1056/NEJMoa066603.

8. Angrisani L, Santonicola A, lovino P, Ramos A, Shikora S, Kow L. Bariatric Surgery Survey 2018: similarities and disparities among the 5 IFSO chapters. Obes Surg. 2021;31(5):1937-48. https://doi.org/10.1007/ s11695-020-05207-7.

9. Mason E, Ito C. Gastric bypass in obesity. Surg Clin North Am. 1967;47(6): 1345-51. https://doi.org/10.1016/S0039-6109(16)38384-0.

10. Madan AK, Harper JL, Tichansky DS. Techniques of laparoscopic gastric bypass: on-line survey of American Society for Bariatric Surgery practicing surgeons. Surg Obes Relat Dis. 2008;4:166-72 discussion 172-3.

11. Elder KA, Wolfe BM. Bariatric surgery: a review of procedures and outcomes. Gastroenterology. 2007;132(6):2253-71. https://doi.org/10.1053/j.gastro.2007. 03.057.

12. Scopinaro N. Biliopancreatic diversion: mechanisms of action and long-term results. Obes Surg. 2006;16(6):683-9. https://doi.org/10.1381/0960892 06777346637.

13. MacLean LD, Rhode BM, Nohr CW. Long- or short-limb gastric bypass? J Gastrointest Surg. 2001;5(5):525-30. https://doi.org/10.1016/S1091-255X(01 )80091-3.

14. Leifsson BG, Gislason HG. Laparoscopic Roux-en-Y gastric bypass with 2metre long biliopancreatic limb for morbid obesity: technique and experience with the first 150 patients. Obes Surg. 2005;15(1):35-42. https:// doi.org/10.1381/0960892052993396.

15. Nergaard BJ, Leifsson BG, Hedenbro J, Gislason H. Gastric bypass with long alimentary limb or long pancreato-biliary limb-long-term results on weight loss, resolution of co-morbidities and metabolic parameters. Obes Surg. 2014;24(10):1595-602. https://doi.org/10.1007/ s11695-014-1245-7.

16. Homan J, Boerboom A, Aarts E, Dogan K, van Laarhoven C, Janssen I, et al. A longer biliopancreatic limb in RouX-en- $Y$ gastric bypass improves weight loss in the first years after surgery: results of a randomized controlled trial. Obes Surg. 2018;28(12):3744-55. https://doi.org/10.1007/s11695-018-3421-7.

17. Swiss Society for the Study of Morbid Obesity and Metabolic Disorders Guidelines. Available from: https://www.smob.ch/de/richtlinien/medizinisch Accessed 29 Mar 2021.

18. Oria EH, Moorehead K. Bariatric Analysis and Reporting System (BAROS). Obes Surg. 1998;8(5):487-99. https://doi.org/10.1381/096089298765554043.

19. Eypasch E, Williams Jl, Wood-Dauphinee S, Ure BM, Schmülling C, Neugebauer E, et al. Gastrointestinal Quality of Life Index: development, validation and application of a new instrument. Br J Surg. 1995;82(2):216-22. https://doi.org/10.1002/bjs.1800820229.

20. Arts J, Caenepeel P, Bisschops R, Dewulf D, Holvoet L, Piessevaux H, et al. Efficacy of the long-acting repeatable formulation of the somatostatin analogue octreotide in postoperative dumping. Clin Gastroenterol Hepatol. 2009;7(4):432-7. https://doi.org/10.1016/j.cgh.2008.11.025.

21. Buse JB, Caprio S, Cefalu WT, Ceriello A, Del Prato S, Inzucchi SE, et al. How do we define cure of diabetes? Diabetes Care. 2009;32(11):2133-5. https:// doi.org/10.2337/dc09-9036. 
22. Clavien PA, Barkun J, de Oliveira ML, Vauthey JN, Dindo D, Schulick RD, et al. The Clavien-Dindo classification of surgical complications. Ann Surg. 2009; 250(2):187-96. https://doi.org/10.1097/SLA.0b013e3181b13ca2.

23. Slankamenac K, Graf R, Barkun J, Puhan MA, Clavien P-A. The comprehensive complication index: a novel continuous scale to measure surgical morbidity. Ann Surg. 2013;258(1):1-7. https://doi.org/10.1097/SLA. 0b013e318296c732.

24. Probst $P$, Zaschke $S$, Heger $P$, Harnoss JC, Hüttner FJ, Mihaljevic AL, et al. Evidence-based recommendations for blinding in surgical trials. Langenbecks Arch Surg. 2019;404(3):273-84. https://doi.org/10.1007/s00423019-01761-6 Springer Verlag.

25. Piaggio G, Elbourne D, Pocock S, Evans S, Altman D. Reporting of noninferiority and equivalence randomized trials: extension of the CONSORT 2010. JAMA. 2012;308(24):2594-604. https://doi.org/10.1001/jama.2012.87802.

26. Schauer P, Ikramuddin S, Gourash W, Ramanathan R, Luketich J. Outcomes after laparoscopic Roux-en-Y gastric bypass for morbid obesity. Ann Surg. 2000;232(4):515-29. https://doi.org/10.1097/00000658-200010000-00007.

27. Schauer P, Bhatt DL, Kirwan JP, Wolski K, Aminian A, Brethauer SA, et al. Bariatric surgery versus intensive medical therapy for diabetes - 5-year outcomes. N Engl J Med. 2017;376(7):641-51. https://doi.org/10.1056/ NEJMoa1600869.

28. Peterli R, Wölnerhanssen BK, Peters $T$, Vetter $D$, Kröll D, Borbély $Y$, et al. Effect of laparoscopic sleeve gastrectomy vs laparoscopic Roux-en-Y gastric bypass on weight loss in patients with morbid obesity: The SM-BOSS randomized clinical trial. JAMA. 2018;319(3):255-65. https://doi.org/10.1001/ jama.2017.20897.

29. Choban PS, Flancbaum L. The effect of Roux limb lengths on outcome after Roux-en-Y gastric bypass: a prospective, randomized clinical trial. Obes Surg. 2002;12(4):540-5. https://doi.org/10.1381/096089202762252316.

30. Ghiassi S, Higa K, Chang S, Ma P, Lloyd A, Boone K, et al. Conversion of standard Roux-en-Y gastric bypass to distal bypass for weight loss failure and metabolic syndrome: 3 -year follow-up and evolution of technique to reduce nutritional complications. Surg Obes Relat Dis. 2018;14(5):554-61. https://doi.org/10.1016/j.soard.2018.01.004.

31. Kraljević M, Süsstrunk J, Köstler T, Lazaridis II, Zingg U, Delko T. Short or long biliopancreatic limb bypass as a secondary procedure after failed laparoscopic sleeve gastrectomy. Obes Surg. 2021;31(1):170-8. https://doi. org/10.1007/s11695-020-04868-8 Springer.

32. Dapri G, Cadière GB, Himpens J. Laparoscopic conversion of Roux-en-Y gastric bypass to distal gastric bypass for weight regain. J Laparoendosc Adv Surg Tech. 2011;21(1):19-23. https://doi.org/10.1089/lap.2010.0298.

33. Shah K, Nergård BJ, Fagerland MW, Gislason H. Limb length in gastric bypass in super-obese patients-importance of length of total alimentary small bowel tract. Obes Surg. 2019;29(7):2012-21. https://doi.org/10.1007/ s11695-019-03836-1.

34. Peterli R, Borbély Y, Kern B, Gass M, Peters T, Thurnheer M, et al. Early results of the Swiss Multicentre Bypass or Sleeve Study (SM-BOSS): a prospective randomized trial comparing laparoscopic sleeve gastrectomy and RouX-en-Y gastric bypass. Ann Surg. 2013;258(5):690-5. https://doi.org/10.1097/SLA. Ob013e3182a67426.

35. Peterli R, Wölnerhanssen BK, Vetter $D$, Nett $P$, Gass M, Borbély $Y$, et al. Laparoscopic sleeve gastrectomy versus Roux-Y-gastric bypass for morbid obesity-3-year outcomes of the prospective randomized Swiss Multicenter Bypass Or Sleeve Study (SM-BOSS). Ann Surg. 2017;265(3):466-73. https:// doi.org/10.1097/SLA.0000000000001929.

36. Peterli R, Wölnerhanssen BK, Peters $T$, Vetter $D$, Kröll D, Borbély $Y$, et al. Effect of laparoscopic sleeve gastrectomy vs laparoscopic Roux-en-Y gastric bypass on weight loss in patients with morbid obesity. JAMA. 2018;319(3): 255-65. https://doi.org/10.1001/jama.2017.20897.

\section{Publisher's Note}

Springer Nature remains neutral with regard to jurisdictional claims in published maps and institutional affiliations.

\section{Ready to submit your research? Choose BMC and benefit from:}

- fast, convenient online submission

- thorough peer review by experienced researchers in your field

- rapid publication on acceptance

- support for research data, including large and complex data types

- gold Open Access which fosters wider collaboration and increased citations

- maximum visibility for your research: over $100 \mathrm{M}$ website views per year

At BMC, research is always in progress.

Learn more biomedcentral.com/submissions 